Introduction: Breast cancer (BC) is a heterogeneous disease. Several subgroups have been identified, according to the clinical presentation and radiographic, pathological, biological, and molecular characteristics of the tumor. Intrinsic genetic heterogeneity may be responsible for these differences. To date, little is known about the clinical features and outcome of patients with primary metastatic BC (PMBC) defined as those presenting with stage IV disease.

Material and methods: Between September 2007 and May 2011, BC patients who were admitted to a clinic were assessed. Patients with PMBC were included in this retrospective analysis. The patients' demographic characteristics, treatment schedules, and survival data were recorded.

Results: Of 2478 BC patients, 102 (4.1\%) with $\mathrm{PMBC}$ were included in the analysis. The median age of the patients was 50 (26-90) years. Only four patients (3.9\%) had previously undergone mammography. The median progression-free survival (PFS) and overall survival (OS) were 30 and 66 months, respectively. The PFS and OS were unaffected by age, menopausal status, ECOG, histology, or tumor grade. Both PFS and OS were affected by HR status (log rank $p=0.006$, log rank $p=0.04)$, HER2 status ( $p=0.001$, $p=0.005)$, site of metastasis $(p=0.01$, $p=0.04)$, radiotherapy $(p=0.04$, OS $p=0.03$ ), and bisphosphonate treatment $(p=0.02, p=0.006)$. PFS was greater in the hormone therapy group (43 months, $p=0.03$ ) while OS was greater in the patients that received chemotherapy (76 months, $p=0.01$ ).

Conclusions: Mammography should be given greater emphasis, considering its importance in the prevention of PMBC. As a treatment option for bone and soft tissue metastatic PMBC patients, hormone therapy should be effective as a first-line treatment.

Key words: primary metastatic breast carcinoma, demographic characteristics, mammography, factors affecting survival.

Contemp Oncol (Pozn) 2013; 17 (5): 450-455 DOI: $10.5114 /$ wo.2013.37543

\section{Assessment of general characteristics of patients with primary metastatic breast carcinoma: single center experience}

\author{
Ummugul Uyeturk ${ }^{1}$, Burcin Budakoglu², ibrahim Turker', Kaan Helvaci², \\ Ozlem Uysal Sonmez ${ }^{2}$, Gulali Aktas', Ulku Yalcintas Arslan², \\ Omur Berna Cakmak Oksuzoglu ${ }^{2}$
}

${ }^{1}$ Abant Izzet Baysal University Faculty of Medicine, Department of Medical Oncology, Bolu, Turkey

${ }^{2}$ Ankara Oncology Education and Research Hospital, Clinical of Medical Oncology, Ankara, Turkey

\section{Introduction}

Breast cancer (BC) is the most common cancer in women in almost all countries, including developing countries. In 2008, 1,380,000 new cases and 458,000 BC deaths were noted worldwide, with 332,000 new cases and 89,000 deaths in the European Union [1, 2]. Breast cancer is a heterogeneous disease with several subgroups based on the clinical presentation and radiographic, pathological, biological, and molecular characteristics of the tumor [3].

Approximately $5-10 \%$ of $B C$ is metastatic at diagnosis; of these, approximately one-fifth of the patients survive for five years. As there are significant variations in the outcome of early $B C$ among different regions, the burden of primary metastatic BC (PMBC) may differ from that of early disease [1]. The general characteristics of the primary tumor are important in the prognosis and survival of patients with MBC [4].

Despite a reduction in $\mathrm{BC}$ mortality by $15 \%$ due to increased awareness of $\mathrm{BC}$ and widespread screening by mammography, the literature lacks data suggesting that mammography reduces the incidence of advanced $B C$ [5]. The prevalence of metastatic disease is high because many women live with the disease for several years. There is, however, a significant lack of accurate data on the prevalence in the great majority of countries, since most cancer registries do not capture relapses [1].

Little is known about the clinical features and outcome in patients with PMBC. The aim of this analysis was to evaluate the demographic characteristics of PMBC patients and the factors that may affect progression-free survival (PFS) and overall survival (OS).

\section{Material and methods}

Between September 2007 and May 2011, BC patients who were admitted to the Clinical Medical Oncology Department of the Ankara Oncology Education and Research Hospital (Ankara, Turkey) were assessed in this retrospective analysis. Patients with PMBC were included in this analysis. Patients were considered to have $P M B C$ if a distant metastasis was evident at the time of the initial diagnosis of BC. Patients with an ipsilateral axillary lymph node metastasis at the time of diagnosis were not included in the PMBC group. Patients were considered to have recurrent metastatic $B C(R M B C)$ if the metastasis had developed during the follow-up period for localized BC. Patients with RMBC were excluded from the analysis. The age, menopausal status, Eastern Cooperative Oncology Group (ECOG) performance status, tumor histological 
subtype, grade of tumor, and type of metastasis (visceral, bone/soft tissue, and visceral plus bone/soft tissue) were recorded from the patients' medical records. Treatment schedules and the duration and response to treatment were also recorded.

Chemotherapy (cyclophosphamide, Adriamycin and taxanes) was used as the first line treatment in patients with visceral metastasis [hormone receptor (HR) negative or positive and if they were human epidermal growth factor receptor 2 (HER2) negative]. Targeted therapy (trastuzumab) was added to the chemotherapy for HER2 positive patients.

Both chemotherapy and targeted therapy were used for HR negative and HER2 positive patients with only bone and soft tissue metastasis. Hormone therapy (tamoxifen in premenopausal patients and anastrozole or letrozole in postmenopausal patients) or chemotherapy was used as a first line treatment option based on oncologist preference if patients were HR positive and HER2 negative.

The PFS was calculated from the date of first diagnosis until disease progression or death. OS was calculated from the date of first diagnosis till death for any reason, or until the date of last contact.

\section{Statistical analysis}

For statistical analysis, SPSS for Windows ver. 15.0 (SPSS, Chicago, IL, USA) was used. Descriptive statistics for discrete variables were compared with the median (minimum-maximum) as categorical variables, and the number of cases (\%) is shown. Categorical variables were tested for a significant association with PFS or OS using log-rank tests of Kaplan Meier survival curves. For each variable, the average PFS and OS times were calculated; $p<0.05$ was considered statistically significant.

\section{Results}

Between September 2007 and May 2011, a total of 2478 BC cases were admitted to our medical oncology clinic; 102 (4.1\%) of those who were identified PMBC as patients were included in this analysis.

All of the patients were female; the median age was 50 years (range: $26-90$ ). Three patients were 30 years old or younger, 44 were between 31 and 49 years, 38 were between 50 and 69 years, and 17 patients were older than 70 years. More than half of the patients (58.8\%) were postmenopausal. The median age of menopause was 51 (range: 43-55) years.

Only four (3.9\%) patients had had previous mammographic screening.

The ECOG performance status was 0-1, 2, and 3 in 71 (69.6\%), 26 (25.5\%), and 5 (4.9\%) patients, respectively.

In all, 92.2\% (94) patients had not undergone primary surgical treatment. As primary surgical treatment, a modified radical mastectomy was performed in three (2.9\%) patients and a lumpectomy in five (3.1\%). The histological subtypes seen were invasive ductal carcinoma (no special type), invasive lobular carcinoma, or other types in 91 (89.2\%), 8 (7.8\%), and 3 (3.0\%) patients, respectively.
Only one patient had a grade 1 tumor, 25 patients had grade 2 tumor, and 59 patients had a grade 3 tumor; the tumor grade was undetermined in 17 patients.

The tumors were positive for HR and HER2, either by immunohistochemical or chromogenic in situ hybridization methods, in 76.5 and $42.2 \%$ of cases, respectively.

When evaluated together, the tumors were negative for both HR and HER2 in 11 cases (10.8\%), HR-negative and HER2-positive in 13 (12.7\%), HR-positive and HER2-negative in 48 (47.1\%), and both HR- and HER2-positive in 30 cases (29.4\%) (Table 1).

The metastatic sites were visceral, bone/soft tissue, or visceral with bone/soft tissue sites in 21 (20.5\%), 43 (42.2\%), and 38 (37.3\%) patients, respectively. Most of the visceral metastatic patients $(11 / 13,84.7 \%)$ were negative for $\mathrm{HR}$ and positive for HER2 (Table 2).

The median PFS and OS were 30 (range: 1-97) and 66 (range: $1-143^{+}$) months, respectively (Figs. 1 and 2). Both PFS and OS were unaffected by age ( $p=0.2$ for both), menopausal status ( $p=0.09$ and 0.9 , respectively), ECOG performance status ( $p=0.07$ and 0.4 , respectively), histology ( $p=0.3$ and 0.6 , respectively), and tumor grade ( $p=0.2$ and 0.7 , respectively).

Table 1. Demographic characteristics of the patients

\begin{tabular}{|c|c|}
\hline & $n(\%)$ \\
\hline $\begin{array}{l}\text { Median age (years, range) } \\
<30 \text { years } \\
\text { 31-49 years } \\
50-69 \text { years } \\
>70 \text { years }\end{array}$ & $\begin{array}{c}50(26-90) \\
3(2.9) \\
44(43.1) \\
38(37.3) \\
17(16.7)\end{array}$ \\
\hline $\begin{array}{l}\text { Menopausal status } \\
\text { premenopausal } \\
\text { postmenopausal }\end{array}$ & $\begin{array}{l}42(41.2) \\
60(58.8)\end{array}$ \\
\hline $\begin{array}{l}\text { ECOG } \\
\text { ECOG 0-I } \\
\text { ECOG II } \\
\text { ECOG III }\end{array}$ & $\begin{array}{c}71(69.6) \\
26(25.5) \\
5(4.9)\end{array}$ \\
\hline $\begin{array}{l}\text { Type of histology } \\
\text { Invasive ductal } \\
\text { Invasive lobular } \\
\text { other }\end{array}$ & $\begin{array}{l}91(89.2) \\
8(7.8) \\
3(3.0)\end{array}$ \\
\hline $\begin{array}{l}\text { Grade of histology } \\
\text { grade I } \\
\text { grade II } \\
\text { grade III } \\
\text { unspecified }\end{array}$ & $\begin{array}{c}1(1.0) \\
25(24.5) \\
59(57.8) \\
17(16.7)\end{array}$ \\
\hline $\begin{array}{l}\text { Hormone receptor } \\
\text { positive } \\
\text { negative }\end{array}$ & $\begin{array}{l}78(76.5) \\
24(23.5)\end{array}$ \\
\hline $\begin{array}{l}\text { HER2 (IHC and CISH) } \\
\text { positive } \\
\text { negative }\end{array}$ & $\begin{array}{l}43(42.2) \\
59(57.8)\end{array}$ \\
\hline $\begin{array}{l}\text { Receptor combinations } \\
\text { HR(-)HER2(-) } \\
\text { HR(-)HER2(+) } \\
\text { HR(+)HER2(-) } \\
\text { HR(+)HER2(+) }\end{array}$ & $\begin{array}{l}11(10.8) \\
13(12.7) \\
48(47.1) \\
30(29.4)\end{array}$ \\
\hline
\end{tabular}

ECOG - Eastern Cooperative Oncology Group, HR - hormone receptor, HER2 - human epidermal growth factor receptor 2, IHC - immunohistochemical, $\mathrm{CISH}$ - chromogenic in situ hybridization 
Table 2. Presence of visceral metastasis according to receptor profile in primary metastatic breast carcinoma patients

\begin{tabular}{lccc} 
Visceral metastasis & $\begin{array}{c}\text { Absent } \\
n(\%)\end{array}$ & $\begin{array}{c}\text { Present } \\
n(\%)\end{array}$ & \\
\hline HR(-)/HER2(-) & $3(27.2 \%)$ & $8(72.8 \%)$ & 11 \\
\hline HR(-)/HER2(+) & $2(15.3 \%)$ & $11(84.7 \%)$ & 13 \\
\hline HR(+)/HER2(-) & $25(52 \%)$ & $23(48.0 \%)$ & 48 \\
\hline HR(+)/HER2(+) & $13(43.3 \%)$ & $17(56.7 \%)$ & 30 \\
\hline Total $n(\%)$ & $43(42.15 \%)$ & $59(57.85 \%)$ & 102 \\
\hline
\end{tabular}

HR - hormone receptor, HER2 - human epidermal growth factor receptor 2

When PFS and OS were evaluated according to estrogen receptor (ER) and progesterone receptor (PR) status, median PFS of the PR positive patients was not different from that of the PR negative subjects ( $p=0.440)$. In contrast, the PFS of the ER positive patients was significantly longer than

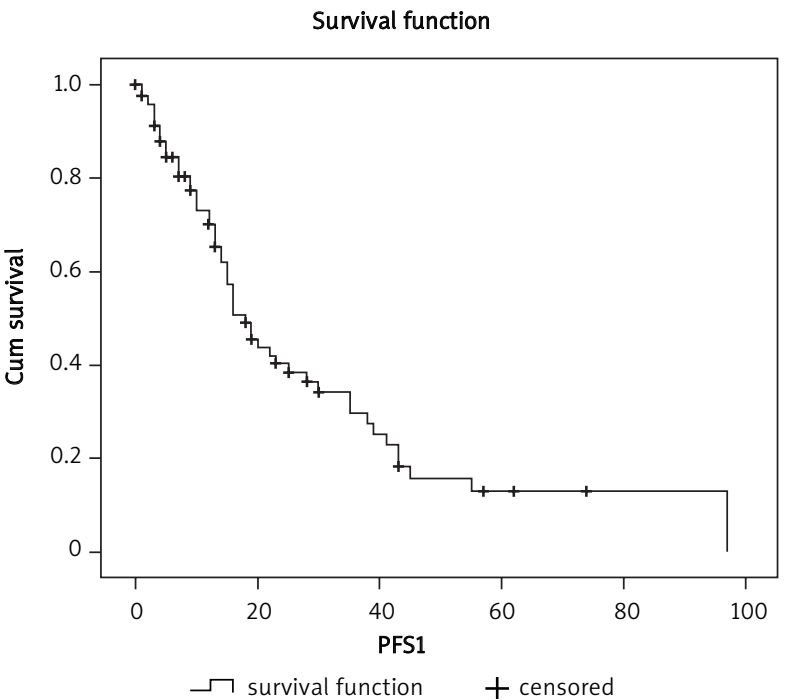

Fig. 1. Kaplan-Meier curve showing the rate of PFS in the patients

Survival function

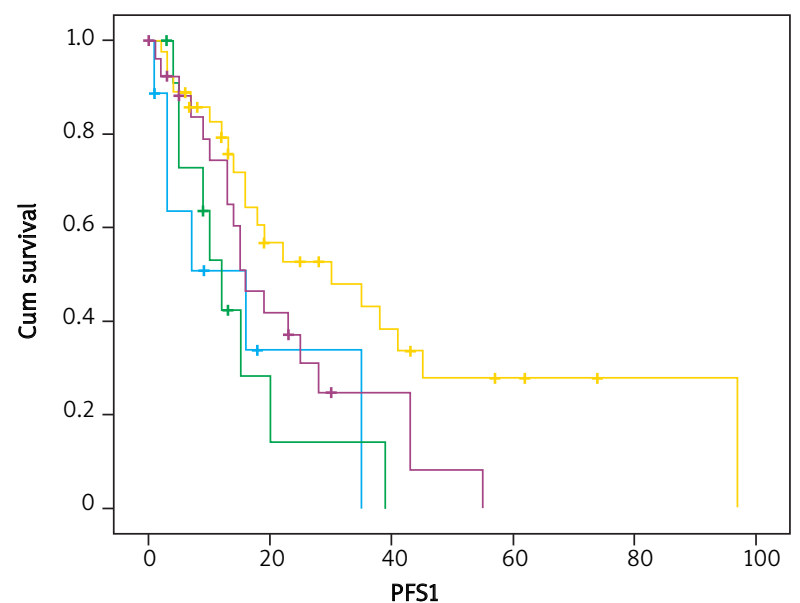

$\neg \mathrm{hr}$-cerbb2- $\neg \mathrm{hr}$-cerbb2+ $\square \mathrm{hr}+$ cerbb2- $\neg \mathrm{hr}+$ cerbb2+

+ hr-cerbb2--censored + hr-cerbb2 +- censored

+ hr+cerbb2--censored + hr+cerbb2+-censored

Fig. 3. Kaplan-Meier curves showing the rate of PFS by HR and HER2 status that of the ER negative patients ( $p=0.011)$. We found that PR and ER status do not have a significant effect on OS ( $p=0.551$ and $p=0.114$ ).

The median PFS of the HR positive and negative patients were 34 (1-97) and 15 (1-39) months, respectively. The median OS of the HR positive and negative patients were 73 (8-143) and 41 (1-67) months, respectively.

Significant effects on both PFS and OS were noted for HR status ( $p=0.006$ and 0.04 , respectively) HER2 status ( $p<0.001$ and 0.005 , respectively), site of metastasis (visceral or bone/soft tissue metastasis; $p<0.01$ and $p=0.04$, respectively), previous radiotherapy ( $p=0.04$ and 0.03 , respectively), and bisphosphonate therapy ( $p=0.02$ and 0.006 , respectively) (Figs. 3 and 4).

The PFS and OS were longer in patients with a metastasis only to bone or soft tissue, as compared to patients with only visceral metastases (40 vs. 13 months, and 79 vs. 34 months, $p<0.001$ and 0.03 , respectively).

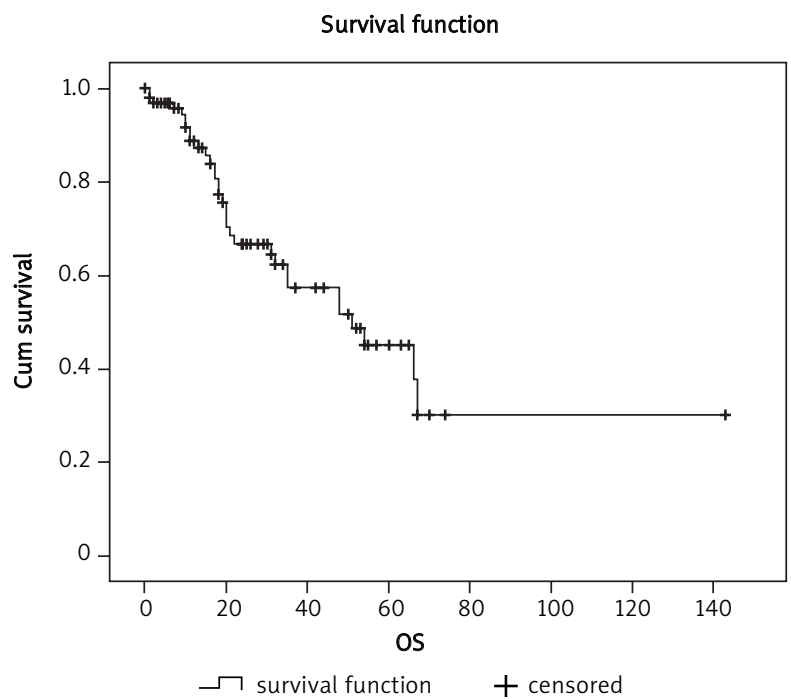

Fig. 2. Kaplan-Meier curve showing the rate of OS in the patients

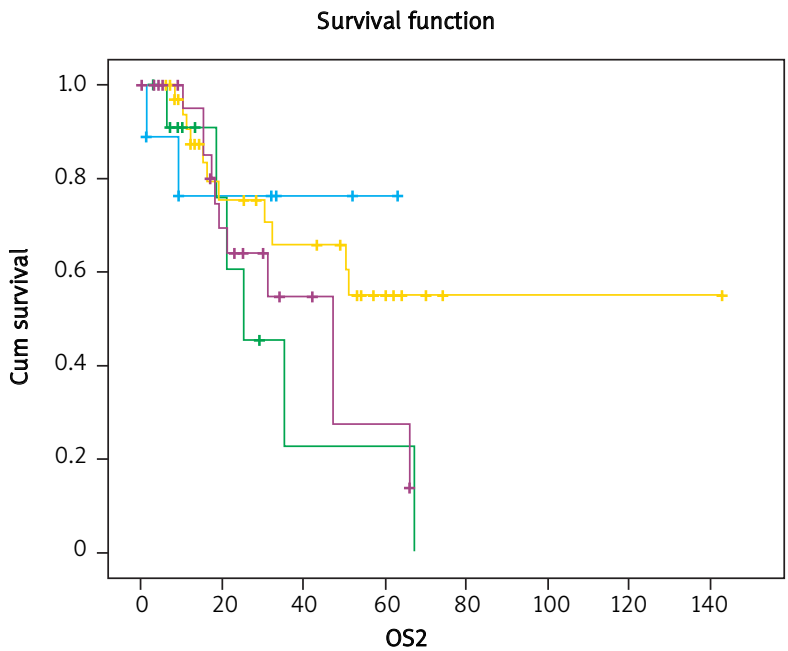

$$
\begin{aligned}
& \neg \text { hr-cerbb2- } \neg \text { hr-cerbb2+ } \square \mathrm{hr}+\text { cerbb2- } \square \mathrm{hr}+\text { cerbb2+ } \\
& + \text { hr-cerbb2--censored }+ \text { hr-cerbb2+-censored } \\
& + \text { hr+cerbb2--censored }+\mathrm{hr}+\text { cerbb2+-censored }
\end{aligned}
$$

Fig. 4. Kaplan-Meier curves showing the rate of OS by HR and HER2 status 
Table 3. Factors affecting progression-free survival and overall survival in primary metastatic breast carcinoma

\begin{tabular}{|c|c|c|c|c|}
\hline Variables & PFS (months) & $p$ & OS (months) & $p$ \\
\hline Median (range) & $30(1-97)$ & & $66(1-143)$ & \\
\hline Age & & 0.2 & & 0.2 \\
\hline Menopausal status & & 0.09 & & 0.9 \\
\hline ECOG performance status & & 0.07 & & 0.4 \\
\hline Type of histology & & 0.3 & & 0.6 \\
\hline Grade of histology & & 0.2 & & 0.7 \\
\hline $\begin{array}{l}\operatorname{HR}(+) \\
\operatorname{HR}(-)\end{array}$ & $\begin{array}{l}34(1-97) \\
15(1-39)\end{array}$ & $0.006^{*}$ & $\begin{array}{c}73(8-143) \\
41(1-67)\end{array}$ & $0.04^{*}$ \\
\hline $\begin{array}{l}\operatorname{HER} 2(+) \\
\operatorname{HER} 2(-)\end{array}$ & $\begin{array}{l}20(1-55) \\
38(1-97)\end{array}$ & $0.04^{*}$ & $\begin{array}{l}37(6-67) \\
93(1-143)\end{array}$ & $0.04^{*}$ \\
\hline $\begin{array}{l}\text { Visceral only metastasis } \\
\text { Bone/soft tissue only metastasis }\end{array}$ & $\begin{array}{l}13(1-38) \\
40(1-97)\end{array}$ & $0.001^{\star}$ & $\begin{array}{c}34(1-70) \\
79(8-143)\end{array}$ & $0.03^{*}$ \\
\hline $\begin{array}{l}\text { Radiotherapy (+) } \\
\text { Radiotherapy (-) }\end{array}$ & $\begin{array}{l}34(1-97) \\
15(1-38)\end{array}$ & $0.005^{*}$ & $\begin{array}{l}70(8-143) \\
33(1-70)\end{array}$ & $0.02^{*}$ \\
\hline $\begin{array}{l}\text { Bisphosphonate }(+) \\
\text { Bisphosphonate }(-)\end{array}$ & $\begin{array}{l}35(1-98) \\
13(1-38)\end{array}$ & $0.01^{*}$ & $\begin{array}{l}72(8-143) \\
31(1-70)\end{array}$ & $0.006^{*}$ \\
\hline $\begin{array}{l}\text { Hormone therapy } \\
\text { Chemotherapy } \\
\text { Chemotherapy and targeted therapy }\end{array}$ & $\begin{array}{l}43(1-62) \\
32(1-97) \\
15(2-30)\end{array}$ & $0.03^{*}$ & $\begin{array}{l}46(16-62) \\
76(1-143) \\
23(10-35)\end{array}$ & $0.01^{*}$ \\
\hline
\end{tabular}

ECOG - Eastern Cooperative Oncology Group, HR - hormone receptor, HER2 - human epidermal growth factor receptor 2, *statistically significant

Both PFS and OS were longer in the group that had received radiotherapy (34 vs. 15 months, and 70 months vs. 33 months, $p<0.005$ and 0.02 , respectively). Bisphosphonate therapy was also associated with a longer PFS and OS (35 vs. 13 months, and 70 vs. 33 months, $p<0.01$ and 0.006 , respectively).

Progression-free survival was better in the hormone therapy (tamoxifen, anastrozole and letrozole) group, while the OS was better in the patients who received chemotherapy

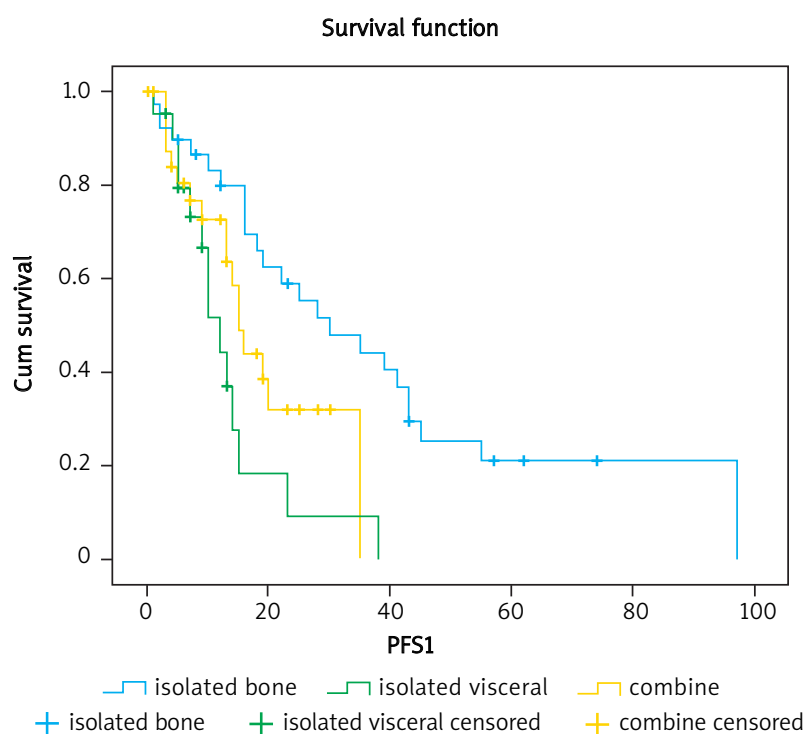

Fig. 5. Kaplan-Meier curves showing the rate of PFS by metastasis region (cyclophosphamide, Adriamycin and taxanes) ( $p=0.03$ and $<0.01$, respectively).

The PFS was longest in the hormone therapy group and shortest in the chemotherapy plus targeted therapy (trastuzumab) group (43 vs. 15 months, respectively; $p=0.03$ ). On the other hand, OS was longest in those patients who received chemotherapy (76 months) and shortest in patients who received chemotherapy plus targeted therapy (23 months; $p<0.01$ ) (Table 3).

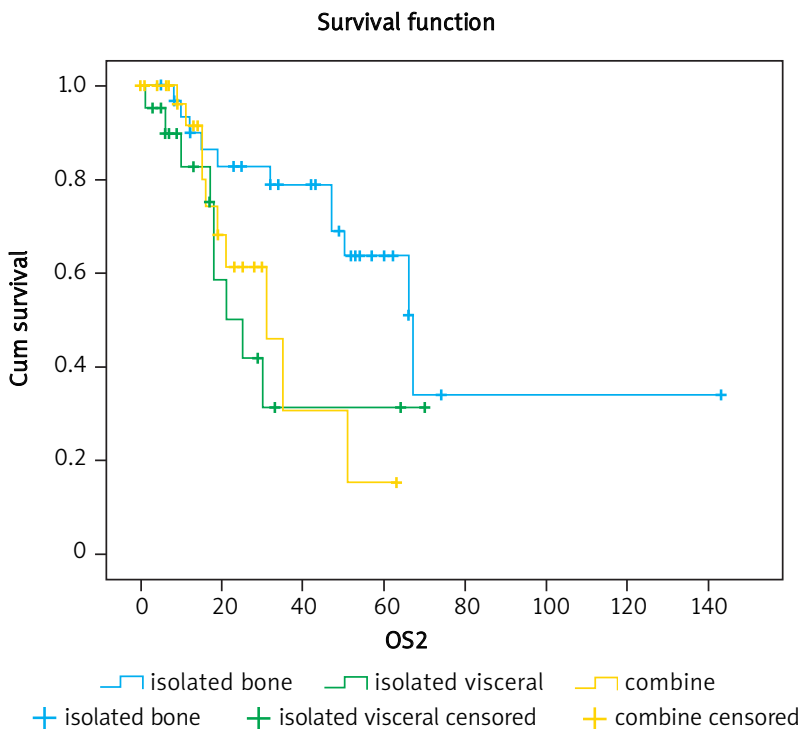

Fig. 6. Kaplan-Meier curves showing the rate of OS by metastasis region 


\section{Discussion}

Breast cancer is a heterogeneous disease, and the clinical course and prognosis for each patient may vary according to the characteristics of the tumor [6]. The incidence of PMBC was reported to be between 0 and $11.5 \%$ in the EUROCARE study [7]. This incidence was reported as 8.9 and $6 \%$ in reports from Spain and the US, respectively $[8,9]$. In this analysis, we found an incidence of PMBC of $4.1 \%$.

The risk of $B C$ increases with age. Two different studies reported that 64 or $70 \%$ of $M B C$ patients were over 50 years of age $[10,11]$. One study indicated that PMBC patients were older (median age: 61 years) than RMBC patients, and that $77.3 \%$ of them were postmenopausal [9]. In our analysis the median age of the patients was $50 ; 54 \%$ of them were older than 50 years, and $58.8 \%$ of the patients were postmenopausal. Age was not directly correlated with PFS or OS. A possible reason for that may be that although many patients in our analysis were elderly, their visceral metastasis rate was low and their bone and soft tissue metastasis rate was high, giving them a better average ECOG performance status.

The best screening method for BC is mammography, which has a sensitivity of $77-95 \%$ and specificity of $94-97 \%$. Annual or biannual mammography screening is advised for women between 40 and 50 years of age. However, women usually do not attend screening programs because of a lack of education and information. We also noted inadequate mammography screening in our analysis [12-14].

Performance status is an important parameter in the initiation and continuation of a treatment. In other MBC studies, the ECOG performance status was 0 or 1 in $58-89.3 \%$ of PMBC patients $[11,15]$. Sezgin et al. [16] showed that a lower performance status was correlated with a worse outcome.

We also found a relatively good performance status for the PMBC patients in our analysis (ECOG of 0 or 1 in $69.6 \%$ of the cases). This might be due to the preponderance of bone and soft tissue metastases, since this kind of metastasis would not highly affect organ functions, and would have a relatively slower clinical progression compared to visceral metastases. In this analysis, we also found a longer PFS and OS in HR-positive patients. Additionally, and as found in the literature, HER2 positivity was correlated with a shorter PFS and OS in our analysis. We also found that the incidence of bone metastases was high (52\%) in the HR-positive/HER2negative subgroup $[6,10,17]$.

As expected, visceral organ metastases were common in the HR-negative/HER2-positive group (84.7\%). These results may explain the better outcome for HR-positive PMBC and worse outcome for HER2-positive PMBC. Studies including PMBC patients reported that the PFS was $<24$ months in patients with a liver or other solid organ metastasis, but $>24$ months in patients with soft tissue/bone metastases only [18]. The detrimental effect of visceral organ metastases is supported by a study from Turkey [16]. In this analysis, we also found a longer PFS and OS in patients with only soft tissue/bone metastases.

Bisphosphonate treatment was also correlated with a better outcome in our analysis. Besides anti-resorptive effects, bisphosphonates also have anti-tumor effects, which may explain these better outcomes. In the ZO-FAST trial, zoledronic acid treatment was correlated with a $41 \%$ relative risk reduction in disease progression [19]. Similarly, zoledronic acid treatment was correlated with lower recurrence rates, and a $36 \%$ relative risk reduction in disease progression, even in premenopausal early BC patients [20].

Palliative radiotherapy was correlated with improved PFS and OS in our analysis. Most of the patients who received radiotherapy presented with bone and soft tissue metastases, so they also received zoledronic acid therapy. This may explain the better outcome in patients receiving radiotherapy.

Trastuzumab, either alone or in combination with chemotherapy, yielded better outcomes for HER2-positive MBC patients, including PMBC cases [21].

Since HER2 positivity is a negative prognostic factor, HER2positive PMBC patients were expected to have a worse outcome than HER2-negative cases. However, trastuzumab therapy was shown to compensate for the poorer prognosis of HER2-positive MBC in previous studies [22, 23].

We found the longest PFS in patients treated with hormone therapy, and the shortest in patients treated with chemotherapy plus targeted therapy. Patients treated with targeted therapy (e.g., trastuzumab) had the worst OS. In contrast to the literature, we did not find any advantage of adding trastuzumab to chemotherapy. This might be due to the worse prognostic features in the HER2-positive patient cohort, due to the retrospective nature of the analysis. We also could not compare treatment with or without trastuzumab, since there were not enough HER2-positive patients treated without trastuzumab.

Treatment choices for PMBC were found to be more aggressive than for RMBC in the literature. The addition of chemotherapy to hormone therapy and combination regimens was preferred more often in PMBC patients, even if they were strongly HR-positive [9]. Although hormone therapy is the standard of care in HR-positive PMBC without disseminated visceral metastasis, many clinicians prefer chemotherapy in initial treatments, even in $\mathrm{PMBC}$ patients with only soft tissue/bone metastases, out of concern for the ineffectiveness of or late response to hormone therapy. Even after treatment with first-line chemotherapy, maintenance with chemotherapy was reported as the treatment of choice, although it was not an evidence-based recommendation $[1,9,17]$.

In this analysis, we found the longest PFS in patients treated with hormone therapy and the shortest in patients treated with chemotherapy plus targeted therapy. This suggests that chemotherapy is not an ideal choice for PMBC patients. Previous studies have shown that hormone therapy, even as a first-line therapy, had a better outcome compared to chemotherapy in postmenopausal women with advanced BC $[9,24]$.

Radiation therapy or bisphosphonates, along with endocrine therapy or chemotherapy, can palliate pain from bony complications. Systemic treatment depends upon HR status, the rate of disease progression, and patient willingness to tolerate the adverse effects of treatment. Endocrine therapy is generally better tolerated than chemotherapy. In women with rapidly progressive disease, it may be better to initiate treatment with chemotherapy, which is more likely to induce a timely response. Trastuzumab with or without 
chemotherapy is a reasonable choice for the initial treatment of metastatic disease overexpressing HER2. Trastuzumab can be used in combination with endocrine therapy for susceptible tumors [25].

The PFS and OS of the patients who underwent primary surgical treatment were not different from those of the patients did not undergo surgical treatment in a series of 61 subjects [26]. In another study the median OS of patients who underwent primary surgical treatment was not significantly different from that of patients who did not. Nevertheless, the authors concluded that surgery should improve the survival in patients with stage IV BC [27]. In our analysis, few patients underwent surgery and so we could not assess the difference.

In conclusion, we found in this analysis that HR positivity, HER2 status, and the site of metastasis were associated with PFS and OS in PMBC patients. As an option, in bone and soft tissue metastatic PMBC, hormone therapy would be effective as the first choice of treatment. Palliative radiotherapy and bisphosphonate treatment of bone metastases should not be neglected. Mammography should be given greater importance in the prevention of PMBC. Our report is a rather small retrospective analysis. These findings should be confirmed with more rigorous reporting and data monitoring in prospective trials of larger populations.

\section{The authors declare no conflict of interests.}

\section{References}

1. Cardoso F, Harbeck N, Fallowfield L, et al.; ESMO Guidelines Working Group. Locally recurrent or metastatic breast cancer: ESMO Clinical Practice Guidelines for diagnosis, treatment and follow-up. Ann Oncol 2012; 23 Suppl 7: vii11-19.

2. Ferlay J, Steliarova-Foucher E, Lortet-Tieulent J, et al. Cancer incidence and mortality patterns in Europe: estimates for 40 countries in 2012. Eur J Cancer 2013; 49: 1374-1403.

3. Burstein HJ, Schwartz RS. Molecular origins of cancer. N Engl J Med 2008; 358: 527

4. Chang EL, Lo S. Diagnosis and management of central nervous system metastases from breast cancer. Oncologist 2003; 8: 398-410.

5. Autier P. Frequency, digital technology, and the efficiency of screening mammography. Ann Intern Med 2011; 155: 554-555.

6. Burstein HJ, Harris JR, Morrow M. Cancer of the breast. Section 2: Malignant tumors of the breast. In: De Vita VT, Lawrence TS, Rosenberg SA (eds.). Cancer principles and practice of oncology. $8^{\text {th }}$ ed. Lippincott Williams \& Wilkins, Philadelphia 2008: 1606-1654.

7. Sant M; Eurocare Working Group. Differences in stage and therapy for breast cancer across Europe. Int J Cancer 2001; 93: 894-901.

8. Jemal A, Siegel R, Xu J, Ward E. Cancer statistics, 2010. CA Cancer J Clin 2010; 60: 277-300.

9. Jimeno A, Amador ML, González-Cortijo L, et al. Initially metastatic breast carcinoma has a distinct disease pattern but an equivalent outcome compared with recurrent metastatic breast carcinoma. Cancer 2004; 100: 1833-1842.

10. Chang J, Clark GM, Allred DC, et al. Survival of patients with metastatic breast carcinoma: importance of prognostic markers of the primary tumor. Cancer 2003; 97: 545-553.

11. Muss HB, Case LD, Richards F, et al. Interrupted versus continuous chemotherapy in patients with metastatic breast cancer. The Piedmont Oncology Association. N Engl J Med 1991; 325: 1342-1348.

12. Karimi P, Shahrokni A, Moradi S. Evidence for U.S. Preventive Services Task Force (USPSTF) recommendations against routine mammog raphy for females between 40-49 years of age. Asian Pac J Cancer Prev 2013; 14: 2137-2139.

13. Pietrzak P, Godlewski D, Adamczak M. Breast cancer screening program attitudes among women from Wielkopolska. The report from Focus Group Interview (FGI) studies. Wspolczesna Onkol 2011; 15: 415-416.

14. Acikgoz A, Ergor G. Compliance with screening recommendations according to breast cancer risk levels in Izmir, Turkey. Asian Pac J Cancer Prev 2013; 14: 1737-1742.

15. Efficace F, Biganzoli L, Piccart M, et al; EORTC-BCG-IDBBC-NDDG. Baseline health-related quality-of-life data as prognostic factors in a phase III multicentre study of women with metastatic breast cancer. Eur J Cancer 2004; 40: 1021-1030.

16. Sezgin C, Zekioğlu O, Gökmen E. Prognostic factors effecting the survival in patients with initially metastatic breast carcinoma. Turkish J Oncol 2006; 21: 20-25.

17. Largillier R, Ferrero JM, Doyen J, et al. Prognostic factors in 1,038 women with metastatic breast cancer. Ann Oncol 2008; 19: 2012-2019.

18. Brufsky A. Trastuzumab-based therapy for patients with HER2-positive breast cancer: from early scientific development to foundation of care. Am J Clin Oncol 2010; 33: 186-195.

19. Eidtmann H, de Boer R, Bundred N, et al. Efficacy of zoledronic acid in postmenopausal women with early breast cancer receiving adjuvant letrozole: 36-month results of the ZO-FAST study. Ann Oncol 2010; 21: 2188-2194.

20. Gnant M, Mlineritsch B, Stoeger H, et al.; on behalf of the Austrian Breast and Colorectal Cancer Study Group, Vienna, Austria. Adjuvant endocrine therapy plus zoledronic acid in premenopausal women with early-stage breast cancer: 62-month follow-up from the ABCSG-12 randomised trial. Lancet Oncol 2011; 12: 631-641.

21. Nicolini A, Giardino R, Carpi A, et al. Metastatic breast cancer: an updating. Biomed Pharmacother 2006; 60: 548-556.

22. Montemurro F, Rossi V, Cossu Rocca M, et al. Hormone-receptor expression and activity of trastuzumab with chemotherapy in HER2-positive advanced breast cancer patients. Cancer 2012; 118: 17-26.

23. Witzel I, Kantelhardt EJ, Milde-Langosch K, et al. Management of patients with brain metastases receiving trastuzumab treatment for metastatic breast cancer. Onkologie 2011; 34: 304-308.

24. Endo Y, Toyama T, Takahashi S, et al. High estrogen receptor expression and low Ki67 expression are associated with improved time to progression during first-line endocrine therapy with aromatase inhibitors in breast cancer. Int J Clin Oncol 2011; 16: 512-518.

25. Maughan KL, Lutterbie MA, Ham PS. Treatment of breast cancer. Am Fam Physician 2010; 81: 1339-1346.

26. Rosche M, Regierer AC, Schwarzlose-Schwarck S, et al. Primary tumor excision in stage IV breast cancer at diagnosis without influence on survival: a retrospective analysis and review of the literature. Onkologie 2011; 34: 607-612.

27. Bafford AC, Burstein HJ, Barkley CR, et al. Breast surgery in stage IV breast cancer: impact of staging and patient selection on overall survival. Breast Cancer Res Treat 2009; 115: 7-12.

\section{Address for correspondence}

Ummugul Uyeturk Assist. Prof.

Department of Medical Oncology

Abant İzet Baysal University Faculty of Medicine

1400 Bolu, Turkey

e-mail: ummuguluyeturk@yahoo.com.tr

Submitted: 21.04.2013

Accepted: $\quad 11.06 .2013$ 